\title{
An observational study on oesophageal variceal endoscopic injection sclerotherapy in patients with portal hypertension seen at the Centre for Clinical Research, Kenya Medical Research Institute
}

\author{
Hudson Lodenyo and Fred A Okoth \\ Kenya Medical Research Institute, P. O. Box 54840, Nairobi, Kenya
}

\begin{abstract}
SUMMARY
Bleeding oesophageal varices still remain a common cause of significant morbidity and mortality in Kenya and is the leading cause of upper gastrointestinal haemorrhage as seen at Kenyatta National Hospital, Nairobi. We report on our experiences in the management of oesophageal varices using injection sclerotherapy. The study site was the Centre for Clinical Research, Kenya Medical Research Institute (KEMRI). Records from structured reporting on procedures and findings during oesophageal variceal injection sclerotherapy were reviewed. All the patients with portal hypertension and previous history of acute variceal blood who underwent endoscopic injection sclerotherapy between August 1998 and May 2001 in the endoscopy unit, KEMRI, had between 2 and 8 sessions of sclerotherapy with 10$15 \mathrm{ml}$ of $5 \%$ ethanolamine oleate during each session. The injection sclerotherapy was done under sedation and pharyngeal local anaesthesia. This was followed by regular surveillance endoscopic examination at 1,3,6 months then yearly. A total of 112 patients underwent vericeal injection sclerotherapy. Male: Female of 2:2:1 and mean age was $32.8 \pm 3.3$ years. Eighty-five (75.9\%) of the patients received at least 4 sessions of injections sclerotherapy. $82.4 \%$ of those who received sclerotherapy upto 4 sessions had regression of varices and $15 \%$ of patients' required more than 6 sessions. The report concludes that variceal injection sclerotherapy is a useful method of treating oesophageal varices and can be performed on an out patient basis.
\end{abstract}

[Afr J Health Sci. 2007; 14:216-218]

\section{Introduction}

Bleeding oesophageal varices are a leading cause of haematemesis in many African countries [1-2]. A study done by Lule and colleagues in 1990-91 showed that bleeding oesophageal varices was the leading cause of haematemesis at Kenyatta National Hospital [1]. Management of portal hypertension with significant oesophageal varices can be divided into 2 broad categories namely pharmacological and non-pharmacological. The non-pharmacological category can further be divided into surgical and nonsurgical. The non-surgical category includes endoscopic variceal injection sclerotherapy endoscopic variceal banding and transjuglar intrahepatic porto systemic shunting (TIPS) [3]. Reports by Jani, Kiire and Omar show that both variceal banding and injection sclerotherapy were effective in reducing or obliterating oesophageal varices thereby reducing the risk of variceal bleed in patients with portal hypertension [3-5]. At KEMRI, endoscopic injection sclerotherapy of oesophageal varices on an outpatient basis inpatients with portal hypertension constitutes about one third of the workload in the endoscopy unit.

Objective

Reports on our experiences in the management of oesophageal varices in-patients with portal hypertension using endoscopic injection sclerotherapy on out-patient basis.

\section{Methodology}

This is a report on all patients with portal hypertension and previous history of acute variceal bleed who underwent endoscopic injection sclerotherapy between August 1998 and May 2001 in the endoscopy unit, Kenya Medical Research Institute.

All patients with portal hypertension who came for injection sclerotherapy had a history of at least an episode of hematemesis. Most patients were outpatients, only a few were inpatients mainly from Kenyatta National Hospital. All patients had large 
bluish varices on commencement of sclerotherapy. The protocol of sclerotherapy was as follows: informed consent was obtained before the procedure, each patient had local pharyngeal anesthesia using xyclocaine spray after which pethidine $(50-100 \mathrm{mg}$ ), Buscopan (hyosane bytylbromide) $(20 \mathrm{mg})$ and Dormican (Midazolum) $(2.5-5 \mathrm{mg})$ were given intravenously; the sclerosant used was $5 \%$ ethanolamine oleate. Two mililiters ( $\mathrm{ml}$ ) of scerosant was injected into each varix or paravariceal and a total of $10-15 \mathrm{ml}$ was used during each session. The patient was allowed a few hours to recover from sedation before discharge on buscopan tablets $20 \mathrm{mg}$ three times for a few days, paracetamol and anti-acids or $\mathrm{H} 2$ receptor antagonists to be taken orally when in pain. The injection was done weekly for the first 4 sessions. Thereafter the injection was given 2 weekly for the $5^{\text {th }}$ and $6^{\text {th }}$ sessions and subsequent sessions until obliteration of varices was achieved. After complete obliteration of the varices, the patients were followed up by surveillance check endoscopy at 1 month, 3 months, 6 months then yearly. Any varices that may reform were detected at surveillance and were injected with sclerosant.

\section{Results}

A total of 112 patients underwent endoscopic injection sclerotherapy between October 1998 and May 2001. Of these, 76 were males and 36 females. The age range was 5 to 71 years. Age distribution is as shown in Table 1.

Table 1: Age distribution

\begin{tabular}{|l|l|l|l|l|l|l|l|}
\hline Age in years & $0-10$ & $11-20$ & $21-30$ & $31-40$ & $41-50$ & $51-60$ & $>60$ \\
\hline Male & 4 & 21 & 91 & 22 & 10 & 8 & 1 \\
\hline Female & 2 & 3 & 21 & 9 & 8 & 1 & 1 \\
\hline
\end{tabular}

Male: female $=2: 1$; Mean age for the study population was $32.8 \pm 3.3$.

Table 2 : Injection sclerotherapy sessions given

\begin{tabular}{|l|l|l|l|l|l|l|l|l|l|l|}
\hline $\begin{array}{l}\text { Number of } \\
\text { sessions }\end{array}$ & 1 & 2 & 3 & 4 & 5 & 6 & 7 & 8 & 9 & 10 \\
\hline Patients & 9 & 10 & 8 & 13 & 12 & 45 & 8 & 2 & 3 & 1 \\
\hline
\end{tabular}

All the patients who received more than 2 injection sclerotherapy sessions had marked reduction in variceal size. Eight five (75.9)\% of the patients received at least 4 sessions and their varices greatly reduced in size by the $4^{\text {th }}$ session. $70(82.4 \%)$ of those who received more than 4 sessions had complete obliteration of the varices by the $6^{\text {th }}$ session. 15 of the patients required more than 6 sessions as shown in Table 2: -

Patients were scheduled to get 6 injection sclerotherapy sessions. Some did not compete the 6 sessions. The patients were not stratified according to the aetiology of portal hypertension and response to treatment and age. However, it was observed that those patients with poor response to treatment had severe liver decompensation and were the ones who required more than six sessions. All patients had retrosternal chest pain after injection for a day or two and required an antispasmodic and paracetamol for pain relief. Ninety percent of the patients had odynophagia for about two days after injection but this cleared spontaneously. Injection site ulceration also occurred in $80 \%$ of patients but ulcers healed on treatment with $\mathrm{H} 2$ receptor antagonist within one week.

\section{Discussion}

Injection sclerotherapy is often carried out on inpatients for fear of bleeding within $24 \mathrm{hrs}$ after injection. We report on injection sclerotherapy carried out on 112 outpatients. The usual way of giving injection sclerotherapy to inpatients is expensive to most patients since they have to pay for the admission. The main reason for admission has been fear of bleeding immediately and within 24 hours after the injection. Hence the need to observe the patient closely in hospital. We did not have any major problem with bleeding after sclerotherapy. However, two patients bled in between sessions and required admission for blood transfusion. One of these patients bled in between sessions and required admission for blood transfusion. One of these 
patients had severe liver disease. It was found out that at least 6 sessions of injection sclerotherapy were required to achieve variceal obliteration as seen in $82.4 \%$ of our cases who received more than 4 sessions. Each session of injection sclerotherapy required $10-15 \mathrm{ml}$ of sclerosant, giving more than $15 \mathrm{ml}$ resulted in severe retrosternal pain. All patients had retrosternal pain but this was relieved by antispasmodics like buscopan, paracetamol antiacids/H2 receptor antagonists. The patients would also have odynophagia soon after injection sclerotherapy but this would disappear within 2 days once the oedema at the injection site regressed. A rather severe complication is variceal ulcer, which might form at injection site and was observed in most cases. The ulcers would be successfully treated with 1-week H2receptor antagonists or proton pump inhibitors. Oesophageal stricture, which occurs within 3 months of sclerotherapy, is a known complication of injection sclerotherapy but we did not get any cases. We conclude that injection sclerotherapy can be carried out successfully on out patient basis.

\section{Acknowledgments}

Director, Kenya Medical Research Institute, Director, Centre for Clinical Research, J Kesusu for computer services and Nursing Staff who work in the Endoscopy Unit.

\section{References}

1. Lule GN, Obiero ET, Ogutu EO. Factors that influence the short-term outcome of upper gastrointestinal bleeding at Kenyatta National Hospital. East African Medical Journal. 1994; 71:240-245.

2. Conn HO, Lebrec D, Terblanche J. The treatment of oesophageal varices: A debate and a discussion. Journal of Internal Medicine. 1997; 241:103-108.

3. Jani PG. Oesophageal variceal banding: Report of the first eight cases in Kenya. East African Medical Journal. 1997; 74: 395-396.

4. Kiire CF, Gangaidzo IT. Sitima J, Ndemera B. Endospcopic sclerotherapy in Zimbabwe. The Central African Journal of Medicine. 1993; 39:177- 180.

5. Omar MM, Fakhry SM, Mostafa I. Immediate endoscopic injection therapy of bleeding oesophageal varices: a prospective Comparative evaluation of injecting materials in Egyptian patients with portal hypertension. Journal of the Egyptian Society of Parasitology. 1998; 28:159-168.
6. Mobiba MC, Koto Z, Lowan TA, Magano S, Segal I, Esser J, Pantanowitz D, Myburgh JA. Distal splenorenal shunt or non-cirrhotic variceal bleeding in black South Africans. South African Journal of Surgery. 1994; 32: 87-90. 